\title{
Economic and Environmental Sustainability through Green Composting: A Study among Low-Income Households
}

\author{
Abdullah Al Mamun ${ }^{1, *}\left(\mathbb{D}\right.$, Naeem Hayat ${ }^{2}{ }^{(}$, Chinnasamy Agamudai Nambhi Malarvizhi ${ }^{3}$ and \\ Noor Raihani Binti Zainol ${ }^{2}$ \\ 1 Faculty of Business and Management, UCSI University, Cheras, Kuala Lumpur 56000, Malaysia \\ 2 Faculty of Entrepreneurship and Business, Universiti Malaysia Kelantan, Pengkalan Chepa, Kota Bharu, \\ Kelantan 16100, Malaysia; naeem.a18e013f@siswa.umk.edu.my (N.H.); raihani@umk.edu.my (N.R.B.Z.) \\ 3 Faculty of Management, Multimedia University, Persiaran Multimedia, Cyberjaya, Selangor 63100, Malaysia; \\ malarvizhi@mmu.edu.my \\ * Correspondence: abdullaham@ucsiuniversity.edu.my or mamun7793@gmail.com; Tel.: +6-0133003630
}

Received: 9 July 2020; Accepted: 7 August 2020; Published: 11 August 2020

\begin{abstract}
Climate change hinders economic growth across the globe, whereas green products and/or the adoption of green practices can effectively mitigate the deteriorating conditions of climate. A large proportion of the world population is living in remote areas with low income, and they should be included in the mitigation efforts to reduce the damaging effects of climate change. Therefore, this study intends to examine the intentions and behaviors towards green composting among low-income rural households to generate income, improve agricultural productivity, and reduce dependency on chemical fertilizers. This study adopted a cross-sectional research design and used structured interviews to collect quantitative data from 420 low-income households living in rural areas in Peninsular Malaysia. This study adopted the Theory of Planned Behavior (TPB) and extended the TPB by embedding the constructs of perceived benefits and eco-literacy into the attitude towards the environment, normative beliefs by extending the subjective norms, and perception of startup resources by extending the perceived behavioral control. The study outcomes revealed that eco-literacy and perceived benefits had a significantly positive effect on attitude towards the environment; normative belief on subjective norms; perception of startup resources on perceived behavioral control; attitude towards the environment on subjective norms; perceived behavioral control on intention towards green composting; and intention towards green composting on green composting adoption behavior. The findings may serve as a guideline to policymakers for the adoption of composting, which can mitigate environmental issues in addition to generating economic activities for low-income residents in Peninsular Malaysia. The study's limitations and future research opportunities are reported as well.
\end{abstract}

Keywords: climate change; economic-ecological sustainability; low-income household; green composting; rural Malaysia

\section{Introduction}

Poverty has been discussed as a significant problem for both developing and underdeveloped countries. Over $10 \%$ of the world's population lives in deplorable conditions by earning less than 2 USD every day with minimum resources to invest in education or start a business without financial and technical support by the local or national institutions [1]. At the same time, emergent ecological issues cause devastating circumstances for the world's environment, as well as social and economic consequences for the society [2]. The rapid spread of economic and industrial development in the 20th and 21st centuries has caused the overuse of natural resources, deterioration of the environment, 
and the by-products of solid waste and greenhouse gas emissions [3]. The poverty rate around the world is increasing with the massive ecological shift that is experienced by poor households and people living near climatically challenging areas [4].

The dual challenges of mitigating ecological impacts and elimination of poverty can be tackled with the progressive behavioral shift of households by tackling ecological issues to preserve the environment and promote income generation $[4,5]$. The adoption of environmentally friendly practices can reduce the adverse effects on the environment more than the currently consumed and practiced conventional products and practices [2,3]. It is claimed that green practices have no deteriorating effect on the environment and have a sustainable principle [6]. Sustainable products have been widely accepted in Malaysia, as consumers are willing to mitigate ecological issues [6-9]. Nonetheless, the acceptance of green practices by low-income households is not extensive, mainly because low-income households are more concerned about poverty issues than the environment.

Furthermore, the willingness to adopt green practices for mitigating the effects of the changing environment depends on the change in attitude (attitude towards the environment (ATE), and subjective norms (SUN) can address the ecological issues across the communities [3,10,11]. Animal manure composting decreases unplanned deposits of animal manure, while enhancing the use of manure as a fertilizer and the generation of biogas [12]. The current adoption of environmentally friendly practices among low-income households is insufficient to mitigate the ecological issues among low-income households.

Poverty elimination is one of the core aims of developmental policy across the globe [13]. The availability of micro-credit and relevant training is the tool of developmental policies. Developmental initiatives are essential to develop and bring the necessary economic growth, as well as to eliminate poverty issues in developing and developed economies.

Low-income households are affected by poverty and environmental degradation [1,4]. Low-income households lack essential food, clean water, necessary health facilities, shelter, and education [1]. Recently, Malaysia has provided economic development that has reduced the incidence of poverty and extreme poverty. However, high income inequality and socio-economic vulnerability are threats for low-income households living in challenging ecological locations in Malaysia, such as the coastal areas. Approximately $40 \%$ of low-income households in Malaysia earn a net household income of less than 3000 MYR (1 MYR = 0.24 USD) [14].

A large population in Malaysia lives in remote areas, wherein agriculture is the core economic activity. Communities that live in rural areas are poor and less educated in addition facing the hardship of climate change. These low-income groups are not included in the efforts to mitigate climate issues. It is believed that low-income groups can bring a positive effect on localities, and their behavior towards climate can overcome environmental issues. Environmental knowledge and learning among low-income households can develop positive ATE and willingness to adopt environmentally friendly practices [13]. This study is concerned with climate and the people living in remote areas with respect to the reduction of climate deterioration and the generation of income sources. The inclusion of low-income households in mitigating environmental issues can reduce the effects of climate change on people living in areas that are severely affected by climate change.

It is vital to achieve the dual goals of uplifting low-income households and addressing environmental issues. As a signatory of the Intergovernmental Panel on Climate Change (IPCC), Malaysia addressed the issue of climate change by adding a notion in the national climate change policy to achieve a sustainable quality of life and ease income incongruence [1,4]. Everyone has a vital role in creating awareness in addressing climate change and poverty issues in Malaysia. This study can contribute to the Malaysian national climate change program by resolving environmental issues through joint participation of the public and improving the nation's competitive position by refining the economic wellbeing of low-income groups. These efforts can help Malaysia to have a competitive position among nations by jointly handling economic and ecological issues. 
Malaysia has been facing ecological issues, and about 1.3 million of the population $(10 \%$ of the total workforce) are engaged with micro- or informal business activities [13]. The literature depicts that consumers tend to avoid environment friendly products due to their cognitive, social, and economic conditions $[7,13]$. Peninsular Malaysia is broadly an agricultural area in which farmers are engaged in animal farming as a source of income. Animal manure from livestock is hazardous to the environment if managed improperly. Composting refers to a biological process of making bio-fertilizer from wastes derived from animals and plants [15]. The correct knowledge, instruments, and resources are essential to transform animal and plant wastes into natural fertilizer via the composting process [4]. Animal manure is the most significant organic waste in Malaysia used for biogas [12]. Bio-fertilizer is a substitute for inorganic fertilizer, which is integral for soil fertility. However, organic bio-fertilizer is difficult to process and is costly. Poor households have animals at home, whereby they can generate income from the manure by selling it to other farmers [15]. Having said this, the study assessed the perceptions of low-income household consumers towards the willingness to adopt environmentally friendly practices or products, such as composting, as well as the adoption of composting as their business to overcome poverty and ecological issues, through an extension of the Theory of Planned Behavior (TPB).

The next section is about the literature on the TPB, which is used to study green product or practice adoption. The subsequent section after the literature review describes the method based on the literature review and the hypothesis development. Sections 4 and 5 present the analysis and results, respectively. Section 6 presents the conclusions with future research opportunities and study limitations.

\section{Literature Review}

\subsection{Theory of Planned Behaviour (TPB)}

The TPB is the most influential theory that elaborates on both behavioral intention and adoption behavior of environmentally friendly products among rice farmers in Malaysia [16]. The TPB states that one's behavior predicted by one's behavioral intention, and behavioral intention depends on social-cognitive factors [2,17]. Attitude towards behaviors determined by the behavioral beliefs of an individual towards the behavior $[2,18]$. The attitude towards behavior, SUN, and perceived behavioral control (PBC) can determine the construction of behavioral intention and vice versa.

Many studies employed the TPB to explore the purchase behavior of environmentally friendly products [3,5,19], customers' intention to stay in green hotels [11], the purchase of organic personal care products [20], the willingness to buy organic food products [21], use of electric cars among consumers [22], and the behavior of paying for environmentally friendly products [18,23].

Although the TPB reflects robustness in describing green and environment-related behavioral decision-making, additional constructs may enhance the explanatory power of TPB, apart from adding more variables to the three basic explanatory constructs of the TPB. Zhang, Yang, and Bi [24] explored the willingness for and adoption of green technologies by extending each exogenous construct of TPB. Chen and Tung [11] extended the TPB with environmental concern and perceived moral obligation for green services. Yadav and Pathak [23] extended the TPB by embedding benefit belief, normative belief, and control belief among participants from a developing country. The rural communities embrace environmentally friendly farming practices to mitigate environmental issues and to create sustainability of agriculture [16]. This study extended the TPB for the adoption of the ecological practice of composting as well as the application and predictive power of the TPB framework.

\subsection{Attitude towards Environment (ATE)}

Attitude refers to the evaluative statement of an individual about a particular behavior. ATE is an individual's evaluation of the behaviors of protecting and conserving the environment [25]. Attitude towards a particular behavior is an active precursor of behavioral intention and the adoption 
of environmental behavior [26,27]. ATE triggered by the behavioral belief and outcome evaluation that the environment should be protected and that eco-literacy (EL) and the conservation of the environment can provide benefits to others, namely perceived benefits (PBs) [28]. Moreover, attitude towards the environment can positively and significantly affect the green behavioral intention $(\beta=0.310$, $p=0.050$ ) [29]. The ATE of small farmers in Malaysia can significantly and positively impact the intention to adopt green practices $(\beta=0.218, p=0.050)$ [16]. Yadav and Pathak [23] revealed that ATE could positively impact the purchase intention (PI) $(\beta=0.350, p=0.001)$ of green products among low-income households in India. Thus, based on the theoretical and existing empirical scholarship, the following hypothesis is proposed:

Hypothesis 1 (H1). ATE has positive effects on intention towards green composting (ITGC).

\subsection{Perceived Benefits (PBs) and Attitude towards Environment}

$\mathrm{PB}$ is the overall assessment of the benefits that one can derive from the adoption of behavior under consideration of what one will receive and give in return [10]. Generally, the change in behavior occurs in green product or green practice adoption when these are perceived as less costly, as a consumer who is dissatisfied with an existing product or practice would spend more time and money to evaluate new products or practices [20]. Consumers of eco-friendly products need to select the products based on the core and green attributes of the products. PB from the green products is positively associated with the development of intention to buy or adopt green and ecologically friendly products and practices [20,28]. Yadav and Pathak [23] recognized that benefit belief (BB) could positively impact ATE $(\beta=0.241, p=0.001)$ for green consumption behavior among low-income households in India. Consumers get engaged in ecological mitigation behavior when they have PB from the use of newly proposed products or practices $[10,30]$. PB for the use of green products has a dynamic role in ATE development. The PB of a green product can positively impact the change of ATE and the behavior of adopting environmentally friendly products and practices like composting $[18,31]$.

Hypothesis 2 (H2). PB has positive effects on ATE.

\subsection{Eco-Literacy (EL) and Attitude towards Environment}

EL is the ability to become ecologically driven and motivated to act pro-environmentally [13]. Being knowledgeable is reflected in all aspects of one's decision-making. Education and knowledge are required to perceive the effects on the environment and to behave in a manner that can lessen the adverse effects of human behavior on the environment. Cheah and Phau [32] tested the effects of EL on the attitude and adoption behavior of consumers. Individuals with EL tend to become more environment-oriented and develop behavior that benefits the environment. Cheah and Phau [32] tested the effects of EL and found that it could significantly affect consumers' attitudes and behaviors towards environmental behaviors. Recently, Al-Mamun et al. [13] established that EL could positively impact the ATE $(\beta=0.152, p=0.000)$ of low-income households in Malaysia. From the above discussion, individuals with EL are more engaged at the cognitive level with the development of positive ATE.

Hypothesis 3 (H3). EL has positive effects on ATE.

\subsection{Subjective Norms (SUN)}

Social pressures have a significant effect on the perception of an individual, and are termed as SUN [33]. Social pressures come from the expectations of significant people of one's surroundings, such as family, friends, relatives, or colleagues [34]. The TPB describes normative beliefs (NB) 
as the social pressures that statistically and significantly impact the intention towards a particular behavior [18]. Individual behavior formation has a significant effect on social expectations, and people try to adopt socially acceptable behaviors. Family, friends, and peers can influence the intention to adopt green behaviors [35], recycling behavior [8], and green purchase intention [6]. Yadav and Pathak [23] revealed that SUN could positively impact the intention for green product purchasing $(\beta=0.223, p=0.001)$ among the low-income households in India. Moreover, social norms can positively and significantly affect green behavioral intentions $(\beta=0.312, p=0.050)$ [25].

Hypothesis 4 (H4). SUN has positive effects on ITGC.

\subsection{Normative Beliefs (NBs) and Subjective Norms}

The NB refers to the level of one's perception of dealing with social pressures in the performance of certain behaviors [18]. An individual considers social pressure when behaving in a manner to meet the expectation of others, such as family, friends, relatives, and colleagues. The belief system helps an individual to evaluate surroundings, which are developed by the interactions of friends and family [36]. The value system at the cognitive level emerges over time and causes the acceptable or unacceptable norms [3]. Family and friends who are involved with the use of environmentally friendly products or practices can influence others to develop a value system where environmental concerns become a relevant and socially acceptable NB to engage in environmental behaviors. Family members and peers can influence others to develop the subjective acceptability of actions. Tonglet, Phillips, and Read [37] tested the effects of recycling practices among peers on the acceptability of starting recycling practices. Nevertheless, the most important precursor of the green purchase intention in Malaysia is peer pressure in the development of the SUN [6]. Yadav and Pathak [23] revealed that NB had positively impacted the SUN ( $\beta=0.343, p=0.001)$ for green consumption behavior among low-income households in India. Based on the TPB and relevant evidence, the following is hypothesized:

Hypothesis $\mathbf{5}$ (H5). NBs have positive effects on SUN.

\subsection{Perceived Behavioral Control (PBC)}

$\mathrm{PBC}$ is the preconception of the resources, opportunities, or threats that may facilitate or restrict the performance of a specific behavior [25]. PBC operates as a precondition of behavioral intention [23]. $\mathrm{PBC}$ has a positive and significant impact on ecological consumers' intentions and actual behaviors [5]. Adnan et al. [22] reported that the intentions of small and poor farmers in Malaysia to adopt green practices are impacted by PBC $(\beta=0.271, p=0.050)$. Among cattle farmers, PBC can significantly affect the intention to adopt conservative practices in Brazil $(\beta=0.208, p=0.10)$ [38] and to sell organic fertilizer to farmers. Recently, Yadav and Pathak [23] recognized that PBC could positively impact the intention to adopt green products $(\beta=0.315, p=0.001)$ among low-income households in India.

Hypothesis 6 (H6). PBC has positive effects on ITGC.

\subsection{Startup Resources (SR) and $P B C$}

The adoption of new ecological products or practices requires a change in routine or resources to adopt the suggested product or practice. For example, green composting is technical, and individuals need the right information and resources before practicing it. Moreover, the availability of the right and timely resources provides the confidence and necessary skills to practice a technical task like composting [39]. However, an individual's perception of the ease or difficulty associated with the availability of SR acts as the control belief and perceived power [40]. One needs to change the current 
behavior into a newly prescribed one. Startup resource availability acts as the control belief, which enables the prospective users to have the perceived control of the intention to adopt green practices. New products or practices like green or ecologically friendly products require resources and skills to use or perform compared to the current practices $[2,36]$. The availability of the resources can positively influence the evaluation, and these factors act as a facilitator for the particular behavior of interest. Moreover, Yadav and Pathak [23] reported that control belief $(\beta=0.091, p=0.001)$ could impact the $\mathrm{PBC}$ for the adoption of green products in India. Based on the above discussion and empirical evidence, this study proposed the following hypothesis:

Hypothesis 7 (H7). SR has positive effects on PBC.

\subsection{ITGC and Green Composting Adoption Behavior (GCAB)}

Intention is the conscious motivation or willingness to be involved in a particular behavior [26]. The intention to adopt green practices is based on how one values the reduction of deplorable effects on the environment [36]. Moreover, it is believed that ecological attitudes, social norms, and PBC can affect the behavioral intention to adopt green practices [20]. In general, intention can significantly predict behavior [25]. Adoption behaviors are the outcomes of intention, as predicted by the TPB [25], whereas ecological product or practice adoption is based on the willingness to adopt green products $[20,41]$, as it decreases the negative impact on the environment and encourages the adoption of an environmentally friendly lifestyle $[19,35,39,42,43]$. The intention to purchase green products can positively and significantly impact $(\beta=0.563, p=0.001)$ purchase behavior [23]. Overall, this study hypothesized the following:

Hypothesis 8 (H8). ITGC has a significant effect on GCAB.

\subsection{The Mediational Roles of ATE, SUN, PCB, and ITGC}

The attitude towards a particular behavior can significantly impact one's PB and EL [23,44]. However, the perception of benefits and EL can impact the intention to adopt green products or practices. Recent work by Al-Mamun et al. [13] reported that environmental concern is mediated by the willingness to pay for eco-friendly products. Moreover, EL is mediated by the attitude towards the willingness to pay for eco-friendly products [21]. This study integrated the dimensions of PB and EL to enhance the predictive power of the original TPB model $[13,23]$. Thus, this study hypothesized the following:

Hypothesis 9 (H9). ATE mediates the relationship between PB, EL and ITGC.

NB affects the subjective norm for the intention to adopt green products [20]. The acceptability from family and friends creates pressures for the individual to think about green products and practices [30,42]. Moreover, the intention to purchase or adopt a green product is influenced by the SUN. It is believed that the SUN acts as a mediator between an individual's NB and intention to adopt green practices $[36,45]$. Therefore, this study posited the following hypothesis:

Hypothesis 10 (H10). The relationship between NB and ITGC is mediated by SUN.

Empirical evidence supported the argument that $\mathrm{PBC}$ has a significant and positive effect on the intention to adopt green practices [2,33]. Any restriction that impacts $\mathrm{PBC}$, such as limitation of resources and external condition, has negative influences on the intention to adopt green practices [16]. Moreover, the perception of behavioral control affects the formation stage of the intention to adopt green practices [13]. Therefore, the following hypothesis is proposed: 
Hypothesis 11 (H11). PBC mediates the relationship between SR and ITGC.

The TPB hypothesized that intention mediates the relationship between predictors such as ATE, SUN, and PBC with the behavior under investigation [23]. Wu and Chen [5] reported that behavioral intention is mediated between the TPB's antecedents (i.e., ATE, SUN, and PBC) and the actual green consumption behavior. Therefore, this study hypothesized the following:

Hypothesis 12 (H12). ITGC mediates the effect of ATE, SUN, and PBC on GCAB.

\section{Research Methodology}

This study adopted a cross-sectional design, and the quantitative data were collected via structured interviews to measure the effect of selected variables on the intention and behavior towards green composting among low-income households in the rural areas of Peninsular Malaysia. All associations that were hypothesized and tested are presented in Figure 1. The study population was composed of low-income households that earned a mean monthly income of 3500 MYR. This study obtained information from low-income households in a Malaysian database that provides specific details, including name, address, and contact details, from selected financial institutions, such as Majlis Amanah Rakyat (MARA), Majlis Agama Islam dan Adat Istiadat Melayu Kelantan (MAIK), Amanah Ikhtiar Malaysia (AIM), and e-Kasih under the Implementation and Coordination Unit of the Prime Minister's Department (ICU-JPM) Malaysia. After receiving the request letter from the researchers, the ICU-JPM provided a list of the names of 110 fund recipients (low-income households) from 11 districts in Kedah from a total of approximately 78,118 people. The financial institutions provided a list of 2953 low-income households that live in nine districts in Kelantan and five districts in Terengganu. A total of 591 low-income households were selected from 114,506 low-income households from the selected financial institutions and the ICU-JPM using random sampling for 22 districts in three states. Amanah Ikhtiar Malaysia (AIM) provided 158 names of financial borrowers (low-income households) from a population of 29,388 people in Terengganu. In addition, Majlis Amanah Rakyat (MARA) provided 2690 names of financial borrowers (low-income households) from the total population of about 4000 people in Kelantan. Majlis Agama Islam dan Adat Istiadat Melayu (MAIK) provided 105 names of fund recipients (low-income households) from the population of 3000 people in Kelantan.

The household heads were contacted to arrange the interview and explain the purpose of the research. Consent was obtained from the respondents through their respective signatures on the survey forms. The interview was conducted in the Malay language, and the interviewees completed the interview forms. The data were collected from 420 respondents via a structured interview. 


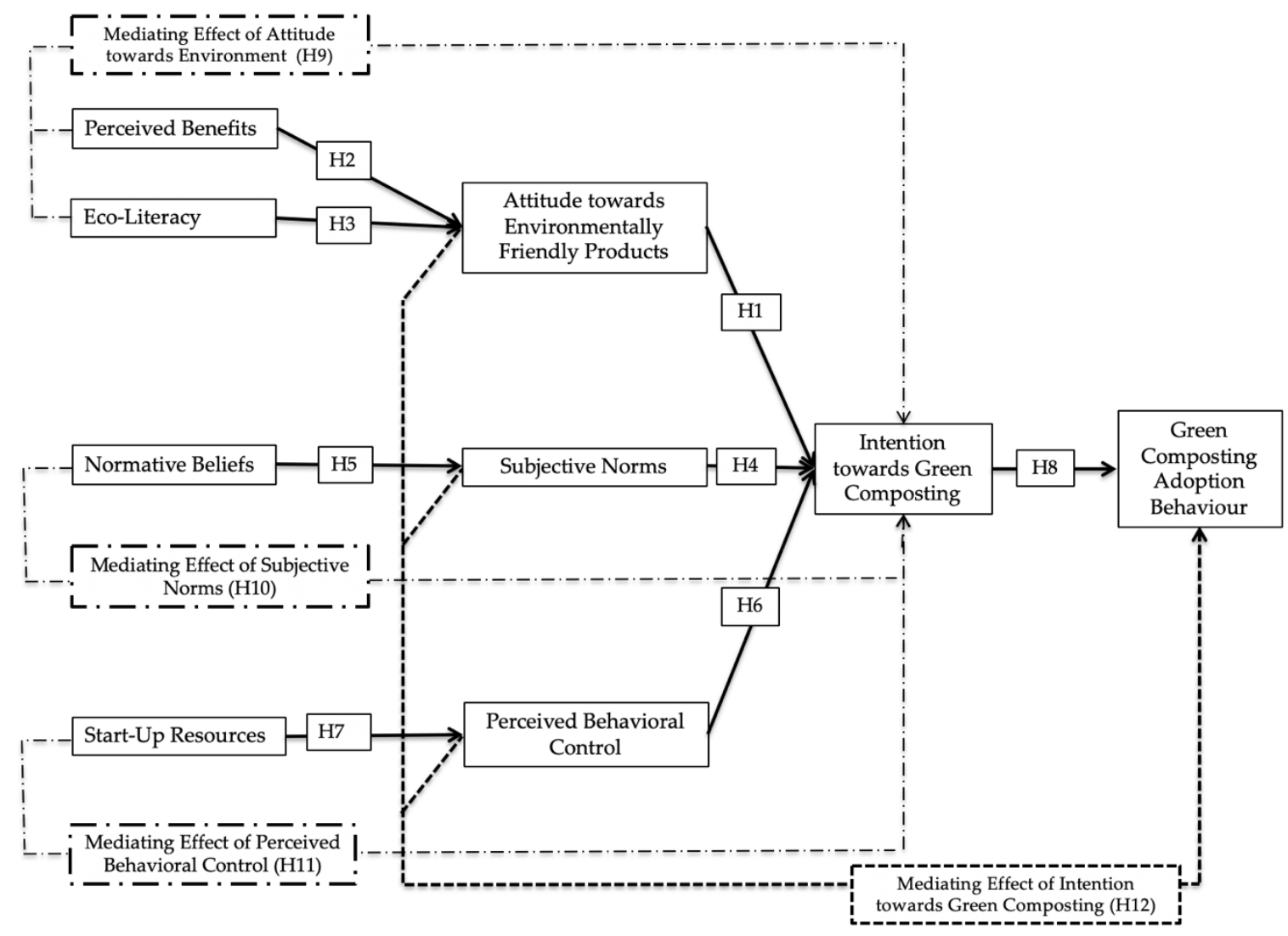

Figure 1. Research model.

\subsection{Sample Selection}

The sample size of this study was estimated using G-Power 3.1 with the power of 0.95 and effect size of 0.15 ; the required sample size was 160 with eight predictors of the model [46]. Moreover, a minimum threshold of 100 samples suggested for the partial least square structural equation modeling (PLS-SEM) [47]. This study collected data from 420 low-income households in 22 districts in three states in the rural areas of Peninsular Malaysia to avoid any possible complications due to the small sample size.

\subsection{Research Instrument}

This study used clear and straightforward words in the items so that the respondents could understand the questionnaire. The items were adapted from previous studies with minor rewording. EL items were adopted from Maichum et al. [43] and Mostafa [19]. The environmental concern items were adapted from Cheung et al. [20] and Maichum et al. [43]. The NB items were adapted from Wu and Chen [5]. PBC items were adapted from Han, Hsu, and Sheu [48]. SR items were adapted from Clark and Douglas [49], ATE items were adapted from Ha and Janda [36] and Maichum et al. [43], SUN items were adapted from Wu and Chen [5] and Maichum et al. [43], and PBC items were adapted from Maichum et al. [43]. Lastly, the items used to measure intentions towards green composting were adapted from Chen and Deng [3] and Maichum et al., [43] and GCAB items were adapted from Walton and Austin [34], Sánchez, López-Mosquera, and Lera-López [50], and Osman et al. [8]. This study used a seven-point Likert scale (1 to 7, from strongly disagree to agree strongly) for the dependent variable and a five-point Likert scale (1 to 5 from strongly disagree to agree strongly) for all independent variables except enterprise recourses, which were determined on whether the respondents possess certain recourses (0 for no and 1 for yes). 


\subsection{Common Method Variance (CMV)}

Both the criterion and the predictor scale format made different to control the CMV [51]. This study applied a range of scale formats for the criterion constructs, such as seven- and five-point Likert scales, for all predictors [51]. Harman's [52] one-factor test was employed to assess the effect of CMV, as prescribed by Podsakoff et al. [51]. Harman's one-factor test explained $30.17 \%$ of variance, which is below the recommended threshold of 50\%, which confirmed the insignificant effect of CMV. Another recommended test is to check if the correlations among the constructs are below 0.9 , which signifies a lack of CMV [53]. The highest correlation among the study constructs was 0.722 between EL and NB, which verified that the data had no common method bias [51].

\subsection{Multivariate Normality}

This study applied the online tool of Web Power to test multivariate normality [54]. The $p$-values, Mardia's multivariate skewness, and a kurtosis coefficient revealed that the data had no non-normality issues, as the $p$-values were less than 0.05 [55].

\subsection{Data Analysis Method}

Partial least squares structural equation modeling (PLS-SEM) was carried out using the Smart-PLS 3.1 tool. The PLS-SEM refers to a multivariate exploratory method to assess the route structures for models with composite and latent constructs [56]. The PLS-SEM allows one to use both non-normal and restricted data collection. The PLS-SEM related to casual-predictive traits and performs complex analysis based on composites without postulation of goodness of fit, while SEM is a covariance-based analysis technique [47]. Data analysis using PLS-SEM contains two phases. The first step deals with model estimation, which evaluates the reliability and validity of the research constructs [56], while model quality assessed based on varied approaches. Step two deals with the evaluation of model correlations, as well as systemic testing of the study model. Study analysis performed with $r^{2}, \mathrm{Q}^{2}$, and effect size, $f^{2}$, explains the change in an endogenous construct caused by exogenous constructs [56].

The importance-performance matrix analysis (IPMA) designates the exogenous model constructs as comparatively high or low according to the importance and performance of the endogenous construct [47]. The IPMA defines and distinguishes the philosophical structure that can maximize the endogenous construct's output from both the management and academic perspectives. As an unstandardized method, IPMA draws on the cumulative impact of rescaled variable scores [57]. Rescaling denotes a score between 0 and 100 for each exogenous latent variable. The mean value of the exogenous latent variable scores indicates the performance of the endogenous latent construct, whereby 0 is the minimum and 100 is the most significant endogenous construct in terms of efficiency [56].

\section{Data Analysis}

\subsection{Descriptive Statistics}

This study collected data from 420 low-income households in the rural areas of Peninsular Malaysia, with a total of 239 females (56.9\%) and 181 males (43.1\%). A total of 167 respondents $(39.8 \%)$ were in the age range between 41 to 50 years old, 111 respondents (26.4\%) from 31 to 40 years old, and 81 respondents (19.3\%) from 51 to 60 years old. The remaining 61 respondents $(14.5 \%)$ were either below 30 or above 60 years old. The following shows the distribution of the respondents' education levels: 251 completed their secondary school (59.8\%), followed by 86 with Sijil Tinggi Persekolahan Malaysia/Diploma (20.5\%), 25 have a bachelor's degree and above (6\%), 54 attended primary school $(12.9 \%)$, and four never attended school (1.0\%). Two hundred sixty-six respondents have business management experience through earlier employment (63.3\%), whereas 354 respondents work full-time $(84.3 \%)$, and 66 of them were part-time employees (15.7\%). A total of 141 respondents are involved in the services sector (33.6\%), 94 in retailing $(22.4 \%)$, and 84 are wholesalers $(20.0 \%)$. The remaining 101 are involved in manufacturing, agriculture, livestock, or other sectors (24\%). 


\subsection{Validity and Reliability}

Table 1 presents the descriptive statistics (number of items, mean, and standard deviation) with the criteria used to evaluate the reliability of items used in this study. Table 1 shows the mean and standard deviation of all the variables. The mean values for startup resources were much lower compared to others because enterprise resources were measured based on whether the respondents possessed certain recourses; 0 represents no and 1 represents yes.

Table 1. Reliability analysis.

\begin{tabular}{ccccccccc}
\hline Variables & $\begin{array}{c}\text { Number } \\
\text { of Items }\end{array}$ & Mean & SD & $\begin{array}{c}\text { Cronbach's } \\
\text { Alpha }\end{array}$ & $\begin{array}{c}\text { Composite } \\
\text { Reliability }\end{array}$ & DG Rho & $\begin{array}{c}\text { Average Variance } \\
\text { Extracted }\end{array}$ & $\begin{array}{c}\text { Variance } \\
\text { Inflation Factor }\end{array}$ \\
\hline PB & 6 & 4.226 & 0.573 & 0.893 & 0.918 & 0.907 & 0.651 \\
EL & 6 & 3.596 & 0.743 & 0.928 & 0.944 & 0.931 & 0.736 \\
NB & 6 & 3.734 & 0.725 & 0.930 & 0.945 & 0.930 & 0.739 & 1.144 \\
SR & 7 & 0.535 & 0.358 & 0.853 & 0.886 & 0.853 & 0.528 & 1.000 \\
ATE & 6 & 3.780 & 0.675 & 0.938 & 0.951 & 0.938 & 0.763 & 1.000 \\
SUN & 5 & 3.427 & 0.668 & 0.892 & 0.920 & 0.892 & 0.698 & 1.347 \\
PBC & 7 & 3.350 & 0.667 & 0.924 & 0.939 & 0.924 & 0.688 \\
ITGC & 8 & 3.213 & 0.666 & 0.926 & 0.939 & 0.926 & 0.659 \\
GCAB & 6 & 3.925 & 1.126 & 0.962 & 0.970 & 0.962 & 0.842 \\
\hline
\end{tabular}

Note: PB: Perceived benefits; EL: Eco-literacy; NB: Normative beliefs; SR: Start-up resources; ATE: Attitude towards environment; SUN: Subjective norms; PBC: Perceived behavioral control; ITGC: Intention towards green composting; GCAB: Green composting adoption behavior.

Based on the recommendations by Hair et al. [56], the composite reliabilities for all of the study's constructs were more than 0.853 , and all the measures were reliable. All the values for the constructs' average variance extracted were more than the prescribed limit of 0.50 , and the results are shown in Table 1. The study's discriminant validity was established with loading and cross-loading, as the results showed that the constructs could establish the discriminant validity. This study used the Fornell-Larcker criterion and Heterotrait-Monotrait ratio to establish the discriminant validity for the study constructs. Table 2 shows the Fornell-Larcker and Heterotrait-Monotrait ratio results, which did not have a lack of discriminant validity for the study constructs.

Table 2. Outer loading and cross-loadings.

\begin{tabular}{cccccccccc}
\hline & PB & EL & NB & SR & ATE & SUN & PBC & ITGC & GCAB \\
\hline PB-Item 1 & 0.812 & 0.267 & 0.362 & 0.131 & 0.395 & 0.199 & 0.211 & 0.224 & 0.197 \\
PB-Item 2 & 0.826 & 0.276 & 0.362 & 0.065 & 0.311 & 0.254 & 0.203 & 0.209 & 0.129 \\
PB-Item 3 & 0.819 & 0.314 & 0.320 & 0.092 & 0.299 & 0.262 & 0.179 & 0.156 & 0.142 \\
PB-Item 4 & 0.839 & 0.286 & 0.297 & 0.057 & 0.267 & 0.288 & 0.216 & 0.165 & 0.105 \\
PB-Item 5 & 0.817 & 0.297 & 0.342 & 0.053 & 0.300 & 0.319 & 0.307 & 0.200 & 0.163 \\
PB-Item 6 & 0.721 & 0.285 & 0.343 & 0.141 & 0.232 & 0.222 & 0.306 & 0.193 & 0.159 \\
EL-Item 1 & 0.284 & 0.827 & 0.562 & 0.284 & 0.358 & 0.304 & 0.342 & 0.217 & 0.181 \\
EL-Item 2 & 0.343 & 0.853 & 0.568 & 0.320 & 0.414 & 0.307 & 0.382 & 0.275 & 0.197 \\
EL-Item 3 & 0.327 & 0.881 & 0.544 & 0.290 & 0.382 & 0.277 & 0.351 & 0.273 & 0.243 \\
EL-Item 4 & 0.323 & 0.870 & 0.584 & 0.281 & 0.335 & 0.229 & 0.327 & 0.227 & 0.197 \\
EL-Item 5 & 0.277 & 0.860 & 0.573 & 0.326 & 0.360 & 0.229 & 0.349 & 0.243 & 0.188 \\
EL-Item 6 & 0.261 & 0.855 & 0.596 & 0.318 & 0.330 & 0.270 & 0.346 & 0.201 & 0.165 \\
NB-Item1 & 0.337 & 0.640 & 0.846 & 0.327 & 0.401 & 0.252 & 0.373 & 0.246 & 0.199 \\
NB-Item 2 & 0.321 & 0.612 & 0.839 & 0.323 & 0.362 & 0.242 & 0.362 & 0.216 & 0.135 \\
NB-Item 3 & 0.409 & 0.552 & 0.856 & 0.243 & 0.460 & 0.315 & 0.343 & 0.246 & 0.214 \\
NB-Item 4 & 0.404 & 0.537 & 0.852 & 0.219 & 0.392 & 0.315 & 0.285 & 0.219 & 0.146 \\
NB-Item 5 & 0.361 & 0.569 & 0.891 & 0.274 & 0.360 & 0.324 & 0.399 & 0.249 & 0.211 \\
NB-Item 6 & 0.323 & 0.548 & 0.874 & 0.299 & 0.346 & 0.305 & 0.385 & 0.225 & 0.127 \\
\hline
\end{tabular}


Table 2. Cont

\begin{tabular}{|c|c|c|c|c|c|c|c|c|c|}
\hline & PB & EL & NB & SR & ATE & SUN & PBC & ITGC & GCAB \\
\hline SR-Item 1 & 0.075 & 0.270 & 0.242 & 0.759 & 0.162 & 0.032 & 0.151 & 0.063 & 0.043 \\
\hline SR-Item 2 & 0.084 & 0.276 & 0.265 & 0.797 & 0.176 & 0.038 & 0.193 & 0.087 & 0.076 \\
\hline SR-Item 3 & 0.070 & 0.295 & 0.272 & 0.784 & 0.218 & -0.035 & 0.191 & 0.066 & 0.070 \\
\hline SR-Item 4 & 0.087 & 0.296 & 0.279 & 0.753 & 0.190 & 0.072 & 0.164 & 0.054 & 0.045 \\
\hline SR-Item 5 & 0.101 & 0.176 & 0.145 & 0.590 & 0.075 & 0.074 & 0.095 & 0.118 & 0.072 \\
\hline SR-Item 6 & 0.123 & 0.210 & 0.168 & 0.649 & 0.147 & 0.097 & 0.104 & 0.102 & 0.067 \\
\hline SR-Item 7 & 0.059 & 0.242 & 0.217 & 0.729 & 0.166 & -0.001 & 0.126 & 0.116 & 0.112 \\
\hline ATE-Item 1 & 0.265 & 0.403 & 0.385 & 0.259 & 0.836 & 0.305 & 0.411 & 0.352 & 0.375 \\
\hline ATE-Item 2 & 0.297 & 0.436 & 0.422 & 0.250 & 0.847 & 0.353 & 0.456 & 0.399 & 0.384 \\
\hline ATE-Item 3 & 0.326 & 0.316 & 0.371 & 0.150 & 0.863 & 0.351 & 0.418 & 0.381 & 0.355 \\
\hline ATE-Item 4 & 0.330 & 0.313 & 0.351 & 0.206 & 0.893 & 0.327 & 0.408 & 0.353 & 0.311 \\
\hline ATE-Item 5 & 0.397 & 0.380 & 0.414 & 0.181 & 0.903 & 0.351 & 0.414 & 0.349 & 0.335 \\
\hline ATE-Item 6 & 0.382 & 0.373 & 0.406 & 0.162 & 0.897 & 0.361 & 0.445 & 0.358 & 0.314 \\
\hline SUN-Item 1 & 0.188 & 0.174 & 0.217 & -0.007 & 0.275 & 0.794 & 0.409 & 0.334 & 0.252 \\
\hline SUN-Item 2 & 0.172 & 0.256 & 0.284 & 0.025 & 0.317 & 0.838 & 0.464 & 0.381 & 0.295 \\
\hline SUN-Item 3 & 0.327 & 0.226 & 0.230 & -0.004 & 0.352 & 0.800 & 0.375 & 0.383 & 0.331 \\
\hline SUN-Item 4 & 0.343 & 0.323 & 0.338 & 0.074 & 0.347 & 0.884 & 0.547 & 0.411 & 0.356 \\
\hline SUN-Item 5 & 0.273 & 0.316 & 0.345 & 0.085 & 0.340 & 0.860 & 0.554 & 0.378 & 0.291 \\
\hline PBC-Item 1 & 0.234 & 0.263 & 0.287 & 0.112 & 0.383 & 0.523 & 0.752 & 0.411 & 0.392 \\
\hline PBC-Item 2 & 0.255 & 0.334 & 0.348 & 0.150 & 0.408 & 0.557 & 0.785 & 0.462 & 0.401 \\
\hline PBC-Item 3 & 0.177 & 0.322 & 0.308 & 0.141 & 0.371 & 0.432 & 0.828 & 0.419 & 0.388 \\
\hline PBC-Item 4 & 0.240 & 0.386 & 0.365 & 0.172 & 0.432 & 0.432 & 0.845 & 0.366 & 0.293 \\
\hline PBC-Item 5 & 0.290 & 0.362 & 0.403 & 0.223 & 0.429 & 0.441 & 0.846 & 0.356 & 0.317 \\
\hline PBC-Item 6 & 0.243 & 0.358 & 0.348 & 0.187 & 0.415 & 0.448 & 0.882 & 0.425 & 0.318 \\
\hline PBC-Item 7 & 0.235 & 0.345 & 0.348 & 0.233 & 0.392 & 0.449 & 0.860 & 0.381 & 0.276 \\
\hline ITGC-Item 1 & 0.118 & 0.296 & 0.302 & 0.181 & 0.371 & 0.280 & 0.416 & 0.747 & 0.495 \\
\hline ITGC-Item 2 & 0.124 & 0.299 & 0.296 & 0.175 & 0.338 & 0.284 & 0.408 & 0.773 & 0.501 \\
\hline ITGC-Item 3 & 0.097 & 0.250 & 0.215 & 0.089 & 0.347 & 0.305 & 0.385 & 0.826 & 0.525 \\
\hline ITGC-Item 4 & 0.248 & 0.232 & 0.237 & 0.116 & 0.344 & 0.372 & 0.384 & 0.856 & 0.541 \\
\hline ITGC-Item 5 & 0.215 & 0.245 & 0.212 & 0.101 & 0.306 & 0.430 & 0.429 & 0.854 & 0.518 \\
\hline ITGC-Item 6 & 0.217 & 0.235 & 0.218 & 0.074 & 0.352 & 0.411 & 0.401 & 0.849 & 0.514 \\
\hline ITGC-Item 7 & 0.264 & 0.129 & 0.136 & -0.019 & 0.327 & 0.423 & 0.364 & 0.792 & 0.473 \\
\hline ITGC-Item 8 & 0.271 & 0.136 & 0.147 & 0.003 & 0.335 & 0.430 & 0.385 & 0.790 & 0.442 \\
\hline GCAB-Item 1 & 0.144 & 0.265 & 0.249 & 0.148 & 0.408 & 0.312 & 0.420 & 0.522 & 0.886 \\
\hline GCAB-Item 2 & 0.113 & 0.245 & 0.228 & 0.136 & 0.372 & 0.274 & 0.392 & 0.522 & 0.891 \\
\hline GCAB-Item 3 & 0.151 & 0.204 & 0.182 & 0.053 & 0.325 & 0.326 & 0.386 & 0.580 & 0.937 \\
\hline GCAB-Item 4 & 0.207 & 0.184 & 0.155 & 0.066 & 0.363 & 0.346 & 0.383 & 0.581 & 0.948 \\
\hline GCAB-Item 5 & 0.201 & 0.174 & 0.146 & 0.052 & 0.354 & 0.364 & 0.350 & 0.603 & 0.928 \\
\hline GCAB-Item 6 & 0.209 & 0.200 & 0.160 & 0.068 & 0.366 & 0.387 & 0.352 & 0.589 & 0.914 \\
\hline \multicolumn{10}{|c|}{ Fornell-Larcker Criterion } \\
\hline PB & 0.807 & & & & & & & & \\
\hline EL & 0.354 & 0.858 & & & & & & & \\
\hline NB & 0.420 & 0.665 & 0.860 & & & & & & \\
\hline SR & 0.112 & 0.354 & 0.322 & 0.726 & & & & & \\
\hline ATE & 0.382 & 0.426 & 0.450 & 0.231 & 0.874 & & & & \\
\hline SUN & 0.315 & 0.316 & 0.343 & 0.046 & 0.392 & 0.836 & & & \\
\hline РBC & 0.289 & 0.409 & 0.415 & 0.210 & 0.488 & 0.568 & 0.829 & & \\
\hline ITGC & 0.239 & 0.281 & 0.272 & 0.111 & 0.419 & 0.453 & 0.489 & 0.812 & \\
\hline GCAB & 0.188 & 0.229 & 0.201 & 0.092 & 0.396 & 0.366 & 0.413 & 0.618 & 0.918 \\
\hline
\end{tabular}


Table 2. Cont.

\begin{tabular}{|c|c|c|c|c|c|c|c|c|c|}
\hline & PB & EL & NB & SR & ATE & SUN & PBC & ITGC & GCAB \\
\hline \multicolumn{10}{|c|}{ Heterotrait-Monotrait Ratio (HTMT) } \\
\hline PB & - & & & & & & & & \\
\hline EL & 0.389 & - & & & & & & & \\
\hline NB & 0.456 & 0.722 & - & & & & & & \\
\hline SR & 0.136 & 0.388 & 0.354 & - & & & & & \\
\hline ATE & 0.406 & 0.451 & 0.480 & 0.248 & - & & & & \\
\hline SUN & 0.353 & 0.339 & 0.367 & 0.099 & 0.426 & - & & & \\
\hline PBC & 0.324 & 0.440 & 0.449 & 0.226 & 0.524 & 0.618 & - & & \\
\hline ITGC & 0.261 & 0.301 & 0.293 & 0.153 & 0.450 & 0.497 & 0.527 & - & \\
\hline GCAB & 0.198 & 0.243 & 0.214 & 0.108 & 0.418 & 0.392 & 0.438 & 0.654 & - \\
\hline
\end{tabular}

Note: PB: Perceived benefits; EL: Eco-literacy; NB: Normative beliefs; SR: Start-up resources; ATE: Attitude towards environment; SUN: Subjective norms; PBC: Perceived behavioral control; ITGC: Intention towards green composting; GCAB: Green composting adoption behavior.

\subsection{Path Analysis}

Table 3 presents the path coefficients. The path value between PB and ATE is 0.264 , with a $p$-value of 0.000 , and the path value between EL and ATE is 0.332 , with a $p$-value of 0.000 . It is revealed that $\mathrm{PB}$ and EL can positively affect ATE among low-income households in the rural areas of Peninsular Malaysia. The $r^{2}$ coefficient of determination for ATE is $24.2 \%$, which has a moderate value. The effect sizes of PB and EL are 0.081 and 0.127 , respectively. Finally, the $\mathrm{Q}^{2}$ for ATE has a medium predictive relevance of 0.175 .

Table 3. Hypothesis testing.

\begin{tabular}{ccccccccccc}
\hline & Hypothesis & Beta & CI-Min & CI-Max & $\boldsymbol{t}$-Values & Sig. & $\boldsymbol{r}^{\mathbf{2}}$ & $\boldsymbol{f}^{\mathbf{2}}$ & $\mathbf{Q}^{\mathbf{2}}$ & Decision \\
\hline H2 & $\mathrm{PB} \rightarrow$ ATE & 0.264 & 0.193 & 0.337 & 6.168 & 0.000 & & 0.081 & & Supported \\
H3 & EL $\rightarrow$ ATE & 0.332 & 0.261 & 0.414 & 7.061 & 0.000 & 0.242 & 0.127 & 0.175 & Supported \\
H5 & NB $\rightarrow$ SUN & 0.343 & 0.265 & 0.425 & 7.323 & 0.000 & 0.118 & 0.134 & 0.077 & Supported \\
H7 & SR $\rightarrow$ PBC & 0.210 & 0.144 & 0.296 & 4.440 & 0.000 & 0.044 & 0.046 & 0.027 & Supported \\
H1 & ATE $\rightarrow$ ITGC & 0.203 & 0.127 & 0.289 & 4.049 & 0.000 & & 0.045 & & Supported \\
H4 & SUN $\rightarrow$ ITGC & 0.224 & 0.136 & 0.300 & 4.349 & 0.000 & 0.315 & 0.048 & & Supported \\
H6 & PBC $\rightarrow$ ITGC & 0.262 & 0.182 & 0.347 & 4.945 & 0.000 & & 0.060 & 0.193 & Supported \\
H8 & ITGC $\rightarrow$ GCAB & 0.618 & 0.565 & 0.673 & 18.782 & 0.000 & 0.382 & 0.619 & 0.310 & Supported \\
\hline
\end{tabular}

Note: PB: Perceived benefits; EL: Eco-literacy; NB: Normative beliefs; SR: Start-up resources; ATE: Attitude towards environment; SUN: Subjective norms; PBC: Perceived behavioral control; ITGC: Intention towards green composting; GCAB: Green composting adoption behavior.

The path value between NB and SUN illustrates the coefficient value of 0.343 with a $p$-value of 0.000 . This result shows that the effect of NB on SUN is positive and statistically significant among the low-income households living in rural areas of Peninsular Malaysia. The individual NB was associated with the perception of SUN. The $r^{2}$, the coefficient of determination for SUN, is $11.8 \%$, which is a moderate value. The effect size of NB on SUN is 0.134 . Finally, the $\mathrm{Q}^{2}$ for SUN has a medium predictive relevance of 0.077 .

The path value between SR and PBC shows a coefficient value of 0.210 with a $p$-value of 0.000 . The results confirm that the effect of SR on $\mathrm{PBC}$ is positive and statistically significant among the low-income households living in rural areas of Peninsular Malaysia. The $r^{2}$, the coefficient of determination for PBC, is $4.4 \%$, which is a low value. The effect size, $f^{2}$, of SR on PBC was 0.046 . Finally, the $\mathrm{Q}^{2}$ for $\mathrm{PBC}$ displayed a medium predictive relevance of 0.027 .

The path value between ATE and ITGC was 0.203 with a $p$-value of 0.000 , the path value between SUN and ITGC was 0.224 with a $p$-value of 0.000 , and the path value between PBC and ITGC was 0.262 with a $p$-value of 0.000 . This result shows that the effects on ATE, SUN, and PBC can positively affect the intention towards green composting among the low-income households living in rural areas of Peninsular Malaysia. The $r^{2}$, the coefficient of determination for ITGC, was $31.5 \%$, which is a moderate 
value. The effect sizes, $f^{2}$, of ATE, SUN, and PBC were $0.045,0.048$, and 0.060 , respectively. Finally, the $\mathrm{Q}^{2}$ for ITGC has a medium predictive relevance of 0.193 .

The path value between the ITGC and GCAB had a coefficient value of 0.618 with a $p$-value of 0.000 . This result shows that the effect of ITGC on GCAB is positive and statistically significant among the low-income households living in rural areas of Peninsular Malaysia. The $r^{2}$, the coefficient of determination for GCAB, was $38.2 \%$, which is a moderate value. The effect size, $f^{2}$, of ITGC on $\mathrm{GCAB}$ was 0.619 . Finally, the $\mathrm{Q}^{2}$ for GCAB exhibited a moderate predictive relevance of 0.310 . All the demographic variables were controlled for the main analysis.

\subsection{Mediating Effects}

Table 4 shows the mediation effect of the ATE tested with hypothesis (H9) for the relationship between PB and ITGC. The result reveals that ATE mediates the relationship between PB and ITGC $(\beta=0.054, \mathrm{CI} \min =0.031, \mathrm{CI} \max =0.081, p=0.000)$. Hypothesis $(\mathrm{H} 9)$ also states that ATE mediates the relationship between EL and ITGC. The result depicts that ATE mediates the relationship between EL and ITGC $(\beta=0.064, \mathrm{CI} \min =0.039, \mathrm{CI} \max =0.106, p=0.001)$. Hypothesis (H10) states that the relationship between NB and ITGC is mediated by SUN. The result shows that SUN mediates the relationship between EL and ITGC $(\beta=0.077, \mathrm{CI} \min =0.045, \mathrm{CI} \max =0.113, p=0.000)$. Hypothesis (H11) states that PBC mediates the relationship between SR and ITGC. The result reveals that PBC mediates the relationship between SR and ITGC $(\beta=0.055, \mathrm{CI} \min =0.031, \mathrm{CI} \max =0.089, p=0.001)$.

Table 4. Meditating effect.

\begin{tabular}{ccccccc}
\hline & $\boldsymbol{\beta}$ & CI-Min & CI-Max & $\boldsymbol{t}$-Value & Sig. & Decision \\
\hline $\mathrm{PB} \rightarrow$ ATE $\rightarrow$ ITGC & 0.054 & 0.031 & 0.081 & 3.395 & 0.000 & Mediation \\
$\mathrm{EL} \rightarrow$ ATE $\rightarrow$ ITGC & 0.067 & 0.039 & 0.106 & 3.282 & 0.001 & Mediation \\
$\mathrm{NB} \rightarrow$ SUN $\rightarrow$ ITGC & 0.077 & 0.046 & 0.113 & 3.751 & 0.000 & Mediation \\
$\mathrm{SR} \rightarrow$ PBC $\rightarrow$ ITGC & 0.055 & 0.031 & 0.089 & 3.206 & 0.001 & Mediation \\
$\mathrm{ATE} \rightarrow$ ITGC $\rightarrow$ GCAB & 0.126 & 0.076 & 0.186 & 3.765 & 0.000 & Mediation \\
$\mathrm{SUN} \rightarrow$ ITGC $\rightarrow$ GCAB & 0.138 & 0.083 & 0.189 & 4.212 & 0.000 & Mediation \\
$\mathrm{PBC} \rightarrow$ ITGC $\rightarrow$ GCAB & 0.162 & 0.110 & 0.216 & 4.745 & 0.000 & Mediation \\
\hline Note: PB: Perceived benefits; EL: Eco-literacy; NB: Normative beliefs; SR: Start-up resources; ATE: Attitude towards \\
environment; SUN: Subjective norms; PBC: Perceived behavioral control; ITGC: Intention towards green composting; \\
GCAB: Green composting adoption behavior.
\end{tabular}

Hypothesis (H12) states that ITGC mediates the relationship between ATE, SUN, PBC and GCAB. The result reveals that ATE mediates the relationship between ATE and GCAB $(\beta=0.126, \mathrm{CI} \min =0.076$, CI $\max =0.186, p=0.000$ ). Hypothesis (H12) also states that the ITGC mediates the relationship between SUN and GCAB. The result reveals that the intention towards green composting mediates the relationship between SUN and GCAB $(\beta=0.138, \mathrm{CI} \min =0.083, \mathrm{CI} \max =0.189, p=0.000)$. Finally, hypothesis (H12) states that ITGC mediates the relationship between PBC and GCAB. The result demonstrates that ITGC mediates the relationship between PBC and GCAB $(\beta=0.162, \mathrm{CI}$ min $=0.110$, $\mathrm{CI} \max =0.216, p=0.000$ ).

\subsection{Importance-Performance Matrix Analysis}

A post-hoc IPMA was executed in PLS-SEM to achieve another research objective. IPMA is used for the target construct; this study used IPMA for the intention towards green composting and GCAB. Table 5 shows the results, in which total effect values show the importance score where values range from 0 to 1 . The performance score ranges from 0 to 100, describing the performance of the variables in the target construct. The results reveal the three most important factors for ITGC for the effect of perceived behavior control (0.264), SUN (0.223), and ATE (0.200). The three most important factors for the intention towards green composting are PB (74.573), NB (66.654), and EL (62.796). 
Table 5. Performance and total effects.

\begin{tabular}{ccccc}
\hline Target Construct & \multicolumn{2}{c}{ Intention towards Green Composting } & \multicolumn{2}{c}{ Green Composting Adoption Behavior } \\
\hline Variables & Total Effect & Performance & Total Effect & Performance \\
\hline PB & 0.063 & 74.573 & 0.066 & 74.573 \\
EL & 0.061 & 62.796 & 0.063 & 62.796 \\
NB & 0.071 & 66.654 & 0.074 & 66.654 \\
SR & 0.101 & 53.454 & 0.106 & 53.454 \\
ATE & 0.200 & 59.183 & 0.210 & 59.183 \\
SUN & 0.223 & 60.595 & 0.233 & 60.595 \\
PBC & 0.264 & 58.767 & 0.276 & 58.767 \\
ITGC & - & - & 1.048 & 52.725 \\
\hline
\end{tabular}

Note: PB: Perceived benefits; EL: Eco-literacy; NB: Normative beliefs; SR: Start-up resources; ATE: Attitude towards environment; SUN: Subjective norms; PBC: Perceived behavioral control; ITGC: Intention towards green composting; GCAB: Green composting adoption behavior.

The results show that the three most important factors for GCAB are ITGC (1.048), PBC (0.276), and SUN (0.233). The three most important factors for the intention towards green composting are the performance of PB (74.573), NB (66.654), and EL (62.796).

\section{Discussion and Implications}

This study explored GCAB among low-income households residing in Peninsular Malaysia through expansion of the TPB. The study's findings revealed that both PB and EL were significantly linked with ATE among the study respondents. These results are in agreement with the findings reported by Cheah and Phau [32], Kai and Haokai [35], and Maichum et al. [43], whereby PB and EL stimulated ATE. Thus, both PB and EL can promote environmental attitudes. The study outcomes support the argument that ATE influences ITGC. This is in line with that reported by Al-Mamun et al. [13] and Wang et al. [33], whereby ATE positively influences intention. The results signify that one's attitude towards the environment determines the intention to try green products and services. Promoting environmental attitudes can enhance the willingness to practice environmentally friendly products and services.

This study further explored the effect of NB on SUN, whereby NB exerted a significant positive effect on SUN. This finding is consistent with that postulated by Adnan et al. [16] and Hultman et al. [42]. The NB in a collective society can build favorable social norms for the intention to accept green products and services. It was found that SUN had significantly affected ITGC among the respondents, which is in agreement with the results reported by Yadav and Pathak [23]. The SUN helps to build a positive intention for the use of green practices. The SUN is imperative for the promotion of green products, as social influence generates social acceptance of green products and services.

Additionally, this study found that SR was significantly related to the PBC among the respondents. Perception of control is high when skills and access to technical details are less [39]. The small significant effect size revealed that SR was indeed significant for PBC, while SR generated less control belief for green composting usage. The findings consistently displayed the positive effect of PBC on ITGC. Similarly, Adnan et al. [22] and Borges et al. [38] claimed that low-income farmers showed interest in the use of green practices. Lastly, the influence of ITGC on GCAB was estimated. As a result, ITGC significantly affected GCAB. The findings are in line with those reported by Al-Mamun et al. [13] and Borges et al. [38], which assert that the intention for green practices leads to the adoption of green practice behavior.

Additionally, this study examined the mediational effect of ATE on the relationships between PB and ITGC, as well as EL and ITGC. The results reflected the significant mediational effect of ATE. Studies by Kai and Haokai [35] and Maichum et al. [43] support these study outcomes. Perception of benefits and environmental learning appeared to facilitate the intention to use green composting through attitude towards the environment. The mediational effect of SUN on the relationship between NB and ITGC was evaluated in this study. The study findings exhibited a significant mediational 
effect of SUN on the relationship between NB and ITGC. Similarly, Al-Mamun et al. [13] depicted that the relationship between normative belief and ITGC was mediated by the prevailing subjective norm. Next, the mediational effect of PBC on the correlation between SR and ITGC had been appraised among the respondents. The study results verified the significant mediational role of PBC on the relationship between SR and ITGC. The study outcomes are supported by the findings postulated by Yadav and Pathak [23]. The results exhibited significant direct and indirect effects of ATE, SUN, and PBC on ITGC. Nevertheless, the study results need to be applied carefully, as the contextual factors significantly influenced ATE, SUN, and PBC for the formation of the intention to use green products or practices [19].

Lastly, the mediating effect of ITGC on the three constructs of TPB (ATE, SUN, and PBC) and GCAB was examined. The results confirmed the significant mediational role of ITCG on the TPB constructs in light of GCAB. The study results are consistent with the findings reported by Qader and Zainuddin [40] and $\mathrm{Wu}$ and Chen [5]. ATE, SUN, and PBC were all significantly mediated by ITGC for GCAB.

\section{Conclusions}

Cognitive and social-economic environmental factors play an essential role in the mass adoption of green practices [35]. This study investigated the possible impact of low-income households' psychological factors of ATE, SUN, and PBC on the intention to adopt green products and green practices in Peninsular Malaysia. This study attempted to extend the TPB with the factors of PB and EL. The statistical analysis confirmed the appropriateness of the extended model for the groups. The existing literature did not focus on the intention of low-income groups to adopt green practices [13]. This study provided considerable support to the current body of knowledge on the adoption of green practices. First, the low-income households living in remote and vulnerable areas can actively take part in ecological practices according to our extension of the existing TPB by adding the sub-components of $\mathrm{PB}$ and EL to ATE, NB to SUN, and perception of SR to PBC. The extension of the TPB permits active engagement of low-income households to develop the willingness to adopt eco-friendly products and practices $[13,23]$. The study's findings reaffirm the applicability of the TPB's extension, which significantly broadens the explanatory power of the TPB for the intention and adoption behavior for green practices among low-income households in Malaysia.

This study can help policymakers to enhance ATE, SUN, and PBC for the adoption of eco-friendly products and practices among low-income households living in more vulnerable areas, like rural areas in Peninsular Malaysia. Both EL and information provided for PB can positively develop the right ATE and can cause further development for the adoption of green products and practices. Moreover, government agencies can play their role in promoting awareness and reducing the perception of being without resources to enhance green composting adoption among low-income households [2,13]. This not only helps in relieving the population of animal waste, but also generates income for low-income households. The relevant authorities should provide training programs to low-income households on adopting green practices, such as composting. Manure can be used to generate electricity and fulfill the increasing demand for electricity in Malaysia [12]. This approach can promote awareness of the environment among low-income households and can help them to have an additional source of income. Moreover, low-income households can mitigate ecological issues. Awareness can generate the ATE and SUN with respect to eco-friendly practices, as training can address the issues of PBC of the intention to engage in composting activities among low-income households.

Nonetheless, all studies, including this study, have limitations. This study only focuses on the low-income households living in remote areas of Peninsular Malaysia, which limited the generalization of its conclusions to only Peninsular Malaysia. The study method is limited by its cross-sectional approach with a single method to gather data from a single source. This method is linked with common method bias, and has drawbacks in terms of robustness and causality. Therefore, future studies should 
adopt multi-method and longitudinal approaches for data collection to enhance both the outcomes and reliability.

This study explored the intention to adopt composting practice among low-income households living in rural areas of Peninsular Malaysia. The adoption of green practices by any community varies based on their circumstances and existing practices. Future studies should focus on a specific product and draw samples from a specific social, economic, and geographic group, enabling them to reveal further details. Moreover, clearer insights may lead to a better understanding of the willingness to adopt eco-friendly products among different groups based on social and economic conditions in order to achieve sustainable development.

Author Contributions: N.H., N.R.B.Z., and C.A.N.M. focused on the conceptualization, methodology, resources, and writing - original draft preparation, A.A.M. focused on the conceptualization, methodology, supervision, and writing-review and editing. All authors have read and agreed to the published version of the manuscript.

Funding: This research received no external funding.

Conflicts of Interest: The authors declare no conflict of interest.

\section{References}

1. World Bank. Poverty and Shared Prosperity 2018: Piecing Together the Poverty Puzzle; World Bank: Washington, DC, USA, 2018.

2. Afroz, R.; Masud, M.; Akhtar, R.; Islam, M.; Duasa, J. Consumer purchase intention towards environmentally-friendly vehicles: An empirical investigation in Kuala Lumpur. Environ. Sci. Pollut. Res. 2015, 22, 16153-16163. [CrossRef] [PubMed]

3. Chen, K.; Deng, T. Research on the green purchase intentions from the perspective of product knowledge. Sustainability 2016, 8, 943. [CrossRef]

4. FAOUN-Food and Agriculture Organization of the United Nations. The Future of Food and Agriculture-Alternative Pathways to 2050. 2018. Available online: http://www.fao.org/3/CA1553EN/ ca1553en.pdf (accessed on 6 August 2019).

5. Wu, S.; Chen, J. A model of green consumption behavior constructed by the theory of planned behavior. Int. J. Mark. Studies 2014, 6, 119-132. [CrossRef]

6. Mei, O.J.; Ling, K.C.; Piew, T.H. The antecedents of green purchase intention among Malaysian consumers. Asian Soc. Sci. 2012, 8, 248-263. [CrossRef]

7. Aminrad, Z.; Zakariya, S.Z.B.S.; Hadi, A.S.; Sakari, M. Relationship between awareness, knowledge and attitudes towards environmental education among secondary school students in Malaysia. World Appl. Sci. J. 2013, 22, 1326-1333.

8. Osman, A.; Isa, F.; Othman, S.; Jaganathan, M. Attitude towards recycling among business undergraduate students in Malaysia. Am. Eurasian J. Sustain. Agric. 2014, 8, 6-12.

9. Tsen, C.H.; Phang, G.; Hasan, H.; Buncha, M.R. Going green: A study of consumers' willingness to pay for green products in Kota Kinabalu. Int. J. Bus. Soc. 2006, 7, 40-52.

10. Chen, M.F. Consumer attitudes and purchase intentions in relation to organic foods in Taiwan: Moderating effects of food-related personality traits. Food Qual. Prefer. 2007, 18, 1008-1021. [CrossRef]

11. Chen, M.F.; Tung, P.J. Developing an extended theory of planned behavior model to predict consumers' intention to visit green hotels. Int. J. Hosp. Manag. 2014, 36, 221-230. [CrossRef]

12. Abdeshahian, P.; Lim, J.S.; Ho, W.S.; Hashim, H.; Lee, C.T. The potential of biogas production from farm animal waste in Malaysia. Renew. Sustain. Energy Rev. 2016, 60, 714-723. [CrossRef]

13. Al-Mamun, A.; Fazal, S.A.; Ahmad, G.B.; Yaacob, M.R.B.; Mohamad, M.R. Willingness to pay for environment-friendly products among low-income households along coastal Peninsular Malaysia. Sustainability 2018, 10, 1316. [CrossRef]

14. DSM-Department of Statistics, Malaysia. Report of Household Income and Basic Amenities Survey 2016. 2017. Available online: https://www.dosm.gov.my/v1/index.php? $\mathrm{r}=$ column/pdfPrev\&id= RUZ5REwveU1ra1hGL21JWV1PRmU2Zz09 (accessed on 22 December 2017).

15. Wezel, A.; Casagrande, M.; Celette, F.; Vian, J.-F.; Ferrer, A.; Peigné, J. Agroecological practices for sustainable agriculture. A review. Agron. Sustain. Dev. 2014, 34, 1-20. [CrossRef] 
16. Adnan, N.; Nordin, S.M.; Abu Bakar, Z. Understanding and facilitating sustainable agricultural pratice: A comprehensive analysis of adoption behaviour among Malaysian paddy farmers. Land Use Policy 2017, 68, 372-382. [CrossRef]

17. Ajzen, I. Residual effects of past on later behavior: Habituation and reasoned action perspectives. Personal. Soc. Psychol. Rev. 2002, 6, 107-122. [CrossRef]

18. Yadav, R.; Pathak, G.S. Young consumers' intention towards buying green products in a developing nation: Extending the theory of planned behaviour. J. Clean. Prod. 2016, 135, 732-739. [CrossRef]

19. Mostafa, M. Antecedents of Egyptian consumers' green purchase intentions. J. Int. Consum. Mark. 2016, 19, 97-126. [CrossRef]

20. Cheung, R.; Lau, M.; Lam, A. Factors affecting consumer attitude towards organic food: An empirical study in Hong Kong. J. Glob. Sch. Mark. Sci. 2015, 25, 216-231. [CrossRef]

21. Tarkiainen, A.; Sundqvist, S. Subjective norms, attitudes and intentions of Finnish consumers in buying organic food. Br. Food J. 2005, 107, 808-822. [CrossRef]

22. Adnan, N.; Nordin, S.M.; Rahman, I.; Rasli, A.M. A new era of sustainable transport: An experimental examination on forecasting adoption behavior of EVs among Malaysian consumers. Transp. Res. A Policy Pract. 2017, 103, 279-295. [CrossRef]

23. Yadav, R.; Pathak, G.S. Determents of consumers' green purchase behaviour in a developing nation: Applying and extending the theory of planned behaviour. Ecol. Econ. 2017, 134, 114-122. [CrossRef]

24. Zhang, B.; Yang, S.; Bi, J. Enterprises' willingness to adopt/develop cleaner production technologies: An empirical study in Changshu, China. J. Clean. Prod. 2013, 40, 62-70. [CrossRef]

25. Ajzen, I.; Fishbein, M. Understanding Attitudes and Predicting Social Behaviour; Prentice-Hall: Boston, MA, USA, 1980.

26. Ajzen, I. The Theory of Planned Behavior. Organ. Behav. Hum. Decis. Process 1991, 50, 179-211. [CrossRef]

27. Brécard, D.; Hlaimi, B.; Lucas, S.; Perraudeau, Y.; Salladarré, F. Determinants of demand for green products: An application to eco-label demand for fish in Europe. Ecol. Econ. 2009, 69, 115-125. [CrossRef]

28. Chen, T.B.; Chai, L.T. Attitude towards the environment and green products: Consumers' perspective. Manag. Sci. Eng. 2010, 4, 27-39.

29. Mancha, R.C.; Yoder, C.Y. Cultural antecedents of green behavioural intent: An environmental theory of planned behaviour. J. Environ. Psychol. 2015, 43, 145-154. [CrossRef]

30. Hansla, A.; Gamble, A.; Juliusson, A.; Gärling, T. Psychological determinants of attitude towards and willingness to pay for green electricity. Energy Policy 2008, 36, 768-774. [CrossRef]

31. Rizwan, M.; Aslam, A.; Rahman, M.; Ahmad, N.; Sarwar, U.; Asgar, T. Impact of green marketing on purchase intention: An empirical study from Pakistan. Asian J. Empir. Res. 2013, 3, 87-100.

32. Cheah, I.; Phau, I. Attitudes towards environmentally friendly products: The influence of eco-literacy, interpersonal influence and value orientation. Mark. Intell. Plan. 2011, 29, 452-472. [CrossRef]

33. Wang, S.; Fan, J.; Zhao, D.; Yang, S.; Fu, Y. Predicting consumers' intention to adopt hybrid electric vehicles: Using an extended version of the theory of planned behavior model. Transportation 2016, 43, 123-143. [CrossRef]

34. Walton, T.; Austin, D. Pro-environmental behavior in an urban social structural context. Sociol. Spectr. 2011, 31, 260-287. [CrossRef]

35. Kai, C.; Haokai, L. Factors affecting consumers' green commuting. Eurasia J. Math. Sci. Technol. Educ. 2016, 12, 527-538. [CrossRef]

36. Ha, H.; Janda, S. Predicting consumer intentions to purchase energy-efficient products. J. Consum. Mark. 2012, 29, 461-469. [CrossRef]

37. Tonglet, M.; Phillips, P.S.; Read, A.D. Using the theory of planned behaviour to investigate the determinants of recycling behaviour: A case study from Brixworth, UK. Resour. Conserv. Recycl. 2004, 41, 191-214. [CrossRef]

38. Borges, J.A.R.; Tauer, L.W.; Lansink, A.G.J.M.O. Using the theory of planned behaviour to identify key beliefs underlying Brazilian cattle farmer's intention to use improved natural grassland: A MIMC modelling approach. Land Use Policy 2016, 55, 193-203. [CrossRef]

39. Paul, J.; Modi, A.; Patel, J. Predicting green product consumption using theory of planned behavior and reasoned action. J. Retail. Consum. Serv. 2016, 29, 123-134. [CrossRef] 
40. Qader, I.; Zainuddin, Y. The influence of media exposure, safety and health concerns, and self-efficacy on environmental attitudes towards electronic green products. Asian Acad. Manag. J. 2011, 16, 167-186.

41. Lanzini, P.; Testa, F.; Iraldo, F. Factors affecting drivers' willingness to pay for biofuels: The case of Italy. J. Clean. Prod. 2016, 112, 2684-2692. [CrossRef]

42. Hultman, M.; Kazeminia, A.; Ghasemi, V. Intention to visit and willingness to pay a premium for ecotourism: The impact of attitude, materialism, and motivation. J. Bus. Res. 2015, 68, 1854-1861. [CrossRef]

43. Maichum, K.; Parichatnon, S.; Peng, K. Application of the Extended Theory of Planned Behavior Model to Investigate Purchase Intention of Green Products among Thai Consumers. Sustainability 2016, 8, 1077. [CrossRef]

44. Voon, J.P.; Ngui, K.S.; Agrawal, A. Determinants of willingness to purchase organic food: An exploratory study using structural equation modelling. Int. Food Agribus. Manag. Assoc. 2011, 14, 103-120.

45. Kim, Y.J.; Njite, D.; Hancer, M. Anticipated emotion in consumers' intentions to select eco-friendly restaurants: Augmenting the theory of planned behavior. Int. J. Hosp. Manag. 2013, 34, 255-262. [CrossRef]

46. Faul, F.; Erdfelder, E.; Lang, A.-G.; Buchner, A. G*power 3: A flexible statistical power analysis program for the social, behavioral, and biomedical sciences. Behav. Res. Methods 2007, 39, 175-191. [CrossRef] [PubMed]

47. Chin, W.W. How to write up and report PLS analyses. In Handbook of Partial Least Squares; Vinzi, V.E., Chin, W.W., Henseler, J., Wang, H., Eds.; Springer: Berlin/Heidelberg, Germany, 2010.

48. Han, H.; Hsu, L.T.J.; Sheu, C. Application of the theory of planned behavior to green hotel choice: Testing the effect of environmentally friendly activities. Tour. Manag. 2010, 31, 325-334. [CrossRef]

49. Clark, D.N.; Douglas, H. Micro-enterprise growth: Lessons from home-based business in New Zealand. Small Enterp. Res. 2014, 21, 82-98. [CrossRef]

50. Sánchez, M.; López-Mosquera, N.; Lera-López, F. Improving pro-environmental behaviours in Spain. The role of attitudes and socio-demographic and political factors. J. Environ. Policy Plan. 2015, 18, 47-66.

51. Podsakoff, P.M.; MacKenzie, S.B.; Lee, J.Y.; Podsakoff, N.P. Common method biases in behavioral research: A critical review of the literature and recommended remedies. J. Appl. Psychol. 2003, 88, 879-903. [CrossRef]

52. Harman, H.H. Modern Factor Analysis; University of Chicago Press: Chicago, IL, USA, 1976.

53. Bagozzi, R.P.; Yi, Y.; Phillips, L.W. Assessing construct validity in organizational research. Adm. Sci. Q. 1991, 36, 421-458. [CrossRef]

54. Peng, D.X.; Lai, F. Using partial least squares in operations management research: A practical guideline and summary of past research. J. Oper. Manag. 2012, 30, 467-480. [CrossRef]

55. Cain, M.K.; Zhang, Z.; Yuan, K.-H. Univariate and multivariate skewness and kurtosis for measuring nonnormality: Prevalence, influence, and estimation. Behav. Res. Methods 2017, 49, 1716-1735. [CrossRef]

56. Hair, J.F.; Risher, J.J.; Sarstedt, M.; Ringle, C.M. When to use and how to report the results of PLS-SEM. Eur. Bus. Rev. 2019, 31, 2-24. [CrossRef]

57. Ringle, C.M.; Sarstedt, M. Gain more insight from your PLS-SEM results: The importance-performance map analysis. Ind. Manag. Data Syst. 2016, 116, 1865-1886. [CrossRef]

(C) 2020 by the authors. Licensee MDPI, Basel, Switzerland. This article is an open access article distributed under the terms and conditions of the Creative Commons Attribution (CC BY) license (http://creativecommons.org/licenses/by/4.0/). 